\title{
Analysing the Effects of Physical Conditions of the Workplace on Employee's Productivity (Including Case Study)
}

\author{
Mohammad Taghipour ${ }^{1,}$,, Maryam Mahboobi ${ }^{2}$, Arash Nikoeifar ${ }^{2}$, Ebrahim Soofi Mowloodi $^{2}$ \\ ${ }^{1}$ Department of Industrial Engineering, Science \& Research Branch of Islamic Azad University, Tehran, Iran \\ ${ }^{2}$ Industrial Engineering, non-profit institution of higher education, Aba, Abyek Qazvin, Iran
}

Email address:

mohamad.taghipour@srbiau.ac.ir (M. Taghipour), mahboobi64@gmail.com (M. Mahboobi), arash2076@gmail.com (A. Nikoeifar), ebrahimmowloodi@gmail.com (E. S. Mowloodi)

\section{To cite this article:}

Mohammad Taghipour, Maryam Mahboobi, Arash Nikoeifar, Ebrahim Soofi Mowloodi. Analysing the Effects of Physical Conditions of the Workplace on Employee's Productivity (Including Case Study). International Journal of Environmental Protection and Policy.

Vol. 3, No. 4, 2015, pp. 111-119. doi: 10.11648/j.ijepp.20150304.15

\begin{abstract}
One of the issues that today will improve the productivity of any organization is attention to the human factors engineering. Experience in worldwide has shown that modifying of work conditions, improving the quality and quantity of production, loss of illnesses due to the work, cost reduction and thereby enhancing the productivity, all are the positive consequences of suitable usage of Ergonomics in organizations which may be feasible under the shadow of following correction system of work condition, paying more attention to the workplaces and applying macro-ergonomics approach. This study was carried out to analyze the environmental and organizational condition of workers in the assembly unit of an automotive company with ergonomics optimization approach. In fact, the aim of this study was to find the amount of employee's satisfaction from environmental and organizational factors of their jobs, thus providing guidelines for improving the identified problems which eventually will lead to increase the productivity. To do this descriptive research, after providing a questionnaire which it is valid and approved final, 50 out of 200 workers of the second shift of assembly unit have been randomly selected and were asked about the condition of the workplace and also disorders while working. After collecting and observing responses, frequency was obtained using diagram. Meanwhile, using mask had the least attention and environment noise had the most frequently in disorder categories. In addition, workers were complaining about the shortage of labor force, high speed of production lines and lack of break time.
\end{abstract}

Keywords: Physical Condition, Micro and Macro Ergonomics, Productivity, Workplace Condition

\section{Introduction}

Today, ergonomics is one of the least known applicable knowledge in country's industrial and services community, while ergonomics paves the way for many management and engineering policies and systems. Of course, modern ergonomics is pretty vaster and developed compared with the past and is still under growth and pervasive in various fields of applied sciences for organizations' management.

Generally, purpose to applying ergonomic knowledge is to reach appropriate and logic relation between employees and environment, machine, job as well as organization. This is a condition in which production and productivity are desirable. Ergonomics can investigate and research employees' psychology and physiology in workplace which is a complicated system between human, machine and environment [1]. Experiences in the industrial counties show that macro-ergonomics is an important and effective factor to initiate suitable workplace. By applying it, more incentive is built in people to participate more and by increasing satisfaction; organization's productivity would be increased $[2,3]$. Regarding macro cases of a system such as management and organizational designing is not a new issue for ergonomists becauseexactly in Europe, there is a belief to resolve ergonomic problems holistically. Macro-ergonomics creates this belief using specific tools and techniques which are resulting in organizational massive scales [4].

Ergonomics plays a key role in identifying causes of incidents and productivity reduction and job quality reduction[5]. Human inadaptability with technology and 
organization can have negative impact not only on system outcome and productivity, but also on staffs' motivation, commitment and also job satisfaction. Experience in the world class has shown positive effect of applying ergonomics in different sectors for modifying job condition, production qualitative and quantitative enhancements, decreasing prevalence of musculoskeletal injuries derived from job, cost reduction and thereby increase in productivity and this issue is under the shadow of following appropriate correction system of working conditions and applying macroergonomics approach[6].

Helali articulates that scholars address importance of applying ergonomics in developing industrial countries for years as an attempt to modify job condition and productivity. Therefore, there is still lack of management awareness about ergonomics in industries of developing industrial countries [2,3]. Hendrick, $\mathrm{H}$ and Kleiner (2007) explain that macroergonomics based designing resolves many of designing principles of micro-ergonomics, because by applying macroergonomics, various principles of micro-ergonomics are spontaneously considered. Therefore, optimal ergonomics consistency between system components with overall system structure, reliability is obtained [8]. In socio-technical system literature, macro-ergonomics provides common optimization of technical subcategories and employees from up to down in the organization. Applying it will cause more guarantee of system optimal effectiveness and efficiency which includes worker's productivity, safety, comfort, inherent incentive and work life quality [7].

In the recent decades, especially about automobile, increase in customer demand has led to accelerate production lines of this product in the country. On the other hand, by intensification of production trend and due to the lack of reform program and system of working condition, health, safety and ergonomic problems in the workplaces especially in developing countries have increased. This issue will cause quality drop and ultimately productivity. This matter is one of the barriers of competition with other firms. Nevertheless, emphasize on job condition modifying in a few number of these firms is mostly emphasize on micro-economics interferences. Results obtained from this approach have been a few and inadequate. Thus, it is required to macro-economic approach is being employed [6]. Today, ergonomic experts have a high trend to apply strong macro-methodology for organization management. By these disorders, apparently, macro-ergonomics is more efficient than traditional ergonomics (which has the direct relation with organising job area).

Current study was carried out to analyze the environmental condition and the reform strategies of working conditions and increasing work life quality and thereby productivity increase in the assembly unit of an automobile company with macro-ergonomics approach. In fact, this study is using macro-ergonomic analysis method to identify workers' ergonomic demands using their participation throughout the process. Proposed macro-ergonomic study in some of the details expresses that how different aspects of micro- ergonomics, Total Quality Management and socio-technical systems can form a triangle with a common approach. In the framework of this method, quality and safety have been introduced as two important performance cases.

To conduct this analytical-descriptive study, after providing questionnaire, among three shifts of mornings, afternoon and night of assembly unit of automobile factory, afternoon shift has been chosen and among workers which are almost 200 persons, 50 persons were asked questions about workplace condition and disorders while working. Some of the macro-ergonomic problems were also proposed by workers in questionnaires. After collecting and checking responses, frequency of the results was obtained using diagram. Also, recommendedstrategies to modify were proposed.

\section{Ergonomics}

Emerging ergonomics dates back to the industrial revolution (at the end of $19^{\text {th }}$ century and beginning of $20^{\text {th }}$ century). Attempts which were simultaneously started during the Second World Wide in the USA and Britain caused ergonomic knowledge to start growth and development and in the most of European countries have been regarded. Unlike other sciences, official date of birth of ergonomic science dates back to $12^{\text {th }}$ of January, 1949 in which for the first time in Britain, a group of scientists and researchers were interested in ergonomic issue and recognizing this new branch of science, but ergonomics was known as a science from the early 1950 s by forming Ergonomic Research Community in Britain [9]. In 1980s, unfortunately, many technological disasters were happened and it caused people to get familiar with ergonomic knowledge more.Plant builders, manufacturers, workers, politicians, and consequently the public have turned to ergonomic designing [10]. Ergonomics has been formed from two parts: Ergo that means job and Nomos that means rules and principles and it is principles of human relations with the job. In one word, ergonomics is a science of optimal applying of tools and people in workplace so that the maximum efficiency would be obtained [11]. Underlying aims of ergonomic science are enhancing how to work, job mythology, job tools and their adaptability with human mental and physical features. Also, ergonomics trends to scientific conformity between job, condition, tool and work environment with human mental and physical features so that workplace and job are designed to be matched with physical features of people average (by considering respective standard deviation) [12]. Since appearing ergonomic knowledge, various definitions of ergonomics have been proposed and these definitions have been gradually got more optimal, accurate and comprehensible. One of them expresses that "Ergonomics is a study between human and job, equipment, environment and specially applying physiologic and psychological knowledge to solve problems". Brazilian Association of Ergonomics also believes that "Ergonomics is a study of human interaction in technology, organization and environment with the aim 
ofintegrated improvement of safety, comfort, welfare and productivity of human activity [9]. Also, International Ergonomic Association knows ergonomic as a scientific field which approaches to study human interactions with different elements of system and applying principles, data and techniques in the projects which are aimed to enhance human welfare and optimize systems' performance [9].

All of definitions have addressed more quality of employees' job, physical dimension, cognitive and organizational features and ergonomist (a person who is responsible for organization ergonomic principles) is attempting to, by minimizing the defective factors, provide more safety and satisfaction and thereby helping organization with enhancing productivity, but generally, in the primary definitions of experts in this filed, ergonomics is more concentrated on human physical factors. Then mental factors were added to this. By mentioning this point that these physical and mental features were used for a human in the past and are remembered as micro-ergonomics, therefore micro-ergonomics is called traditional ergonomics. But, improvements occurred in ergonomics caused traditional definitions were replaced by the modern definitions. In this new definition, "System" term was used as anything which is not human. Regardless of accurate definition proposed by International Ergonomics Association (IEA), modern ergonomics can be defined as the following: Human- System Interface Technology and optimizing human relation with the system. System sector in this definition also is divided into 4 subsystems which are: machine, environment, software, job and organization in which human relation with each of these subsystems is known Hardware-Ergonomics, EnvironmentErgonomics, Cognitive-Ergonomics, and Work DesignErgonomics, respectively. The four first subsystems are known as micro-ergonomics. Accordingly, ergonomics can be regarded in 2 parts: 1) micro-ergonomics which is concentrating on one human 2) macro-ergonomics which is concentrating on the organization (more than one human). In fact, micro-ergonomics considers physical designing of job environment and job tool. Macro-ergonomics wants to optimize organizational and job system designing via considering personnel, technologic and environmental variables and interactions between them, in terms of history, micro-ergonomics is a classic ergonomics which has 50 years history, while macro-ergonomics is a modern ergonomics and has one decade history. In fact, ergonomic objectives were developed since 1980s. This developed version is called macro-ergonomics which is technology application and development in human-machine relation (socio-technical system) in a macro class or in another hand in all over the organization. By this description, ergonomics is exited from micro area and it is more powerful to coordinate hundreds and maybe thousands of workers with systems, equipment and machineries. The main purpose of ergonomics is to evaluate and promote productivity through a specific method. Four primary subsystems include environmental, technological, organizational and individual variables which are interfering systematic inactions between people and job
[13]. As it was mentioned macro-ergonomic based designing also meets many of micro-ergonomic needs and guarantees system as a result of ergonomic adaptability of system components with system overall structure. Macroergonomics is conceptually defined as a top-down sociotechnical approach of systems for designing organizational structures of work and jobs related to human-machine, human-environment and user-system.Qualitymanagement and ergonomics were appropriately emerged during history after socio-technical systems theory which is a basis for integrated method required by organizations [13].

\section{Productivity}

In the literatures of scientific fields related to the organization such as management, economy and sociology, the best functional form of an organization has been defined synergy which has been interpreted as a high productivity. Today, productivity in organizations has been regarded by the majority of managers. Productivity can be interpreted as the sum of effectiveness and efficiency. In another document, productivity is to achieve the maximum possible profit using and taking advantage of job force, ability, human resource skill and talent in order to promote society's welfare. It can be articulated that the word "Productivity" was firstly developed by a person namedQuizni in 1776. After one century, that is 1833, a person named Litr defined productivity as a power and ability to produce.

Productivity has been considered equivalent to indices such as efficiency, effectiveness, performance, beneficiary, innovation, quality, culture, work life quality and so on. Due to this issue that in each of different scientific fields, special definitions and inferences of productivity have been proposed, in managers' viewpoint also, productivity due to roles, their knowledge and skills, coworkers, subordinates and condition in which they are working is different with others. In sum, it can be said that the most comprehensible definitions proposed about productivity belong to the managers. In mangers' viewpoint, productivity is including all of organizational aspects which are important in its function. In this viewpoint, productivity has been considered equivalent to efficiency, effectiveness, performance, products' quality and stakeholders' satisfaction and so on .

World modern science has solved majority parts of individual problems in the various job systems. In this regard, there are many scientific methods which are analyzing different angles of human health and hygiene and also their efficiency as a part of way to reachproductivity. One of them is ergonomics science. Also, less activity can be found that is free from any kind of threating factor. Accordingly, protection and preservation of human resources is arisen as an imperative mission. Paying more attention to human factors in each organization is undoubtedly one of the most important principles and criteria in the organization, because organizations without using human resource are in fact unreliable. Human work is the outcome of various and diverse variables. Sometimes, work is derived from human 
variables such as character, perception and attitudes and sometimes, it is influenced by variables which have physical nature. These variables are called work environment. Today, it was verified that condition of work environment such as noise and health all are affecting on individual performance.Marilyn Joyce, president of the Joyce Foundation in Seattle, America, believes that now this belief has been generalized that firms which are considering quality control and productivity, are using ergonomics as a commercialtalent. Successful firms have combined ergonomic programs with safety, quality control and production plans to reach the maximum profit [14].

\section{Data Collection}

Studied sector is assembly unit of automobile factory. This sector was chosen because of productions' qualitative and productivity drop and also inappropriatework condition of workers in this unit and complaint of inconsistencies between work, work environment and workers' job. Since, in assessments done by ergonomists, workers' participation seems pretty necessary to accelerate finding problems, applying appropriate changes and enhancing work condition. But, survey from workers has been considered as an assessment basis. Approximately, 630 male workers aged between 28-44 years old are working in three shifts in the assembly unit.Work shifts are from 7:30 to $15: 30$ and 15:30 to 23:30 and 23:30 to 7: 30 . In each shift, around 210 workers are working. To survey workers, a questionnaire including questions about rate of workers satisfaction from workplace condition and barriers which causelack of progress in their work and thereby decreasing productivity was provided. Then, among the second shift workers, 50 persons were randomly chosen and they were asked questions about their work environment condition. Also, at the end of questionnaire, they were asked to mention other cases which haven't been brought in questions and cause interruption in their job. Due to this issue that our case study includes one fourth of workers of a work shift, therefore frequency diagram of outcomes has been drawn by Excel software.

\section{Results}

Results obtained from survey have been brought in table 1:

Table 1. Data obtained from 50 compliment questionnaires of workers (Number of agreed workers with each item)

\begin{tabular}{llll}
\hline Questions Response (Number of agreed) & High & Average & Low \\
\hline Workplace space & 3 & 36 & 11 \\
Space allocated to your work & 2 & 18 & 30 \\
Noise rate in work environment & 32 & 12 & 6 \\
Environment temperature & 0 & 34 & 16 \\
Machineries' safety & 2 & 32 & 16 \\
Using mask while working & 0 & 11 & 39 \\
Surface inequality & 28 & 16 & 6 \\
Health and sanitation at work environment & 5 & 19 & 26 \\
Drinking water health & 0 & 25 & 25 \\
Work environment pollution (soldering & 28 & 17 & 5 \\
smoke etc.) & & & \\
\hline
\end{tabular}

Of course in this regard, in addition to the aforementioned cases, workers have mentioned other cases causing idsiorders in their work which are being investigated, but in sum, results showed that in spite of growth, development of assembly unit, environment and job condition provided for workers, positive opinion is not proposed and they are doing their duties in a condition which is far from ideal.

\section{Discussion}

Some of the environmental, organizational, physical and equipment factors which cause disorders in work trend and eventually decreasing quality and productivity will be evaluated using data in table 1 :

\subsection{Environmental Factors}

\subsubsection{Noise}

Job performance can be harmed by the noise, it can be articulated that work environment noise is a very dangerous attacker, because it destroys a number of auditory cells every day. When a worker or employee finds an auditory loss, it is very late, because hardness of hearing or deafness caused by noise is irreversible. Damage derived from noise is not just limited to the ears, but it surrounds all over the body. Noise has its direct or indirect effect through bothersome or job dissatisfaction [15]. Although, many of primary studies showed that industrial workers can do their duties without effects derived from noise, but the recent studies have shown another results. For example, Bragdon showed that noise especially when is unexpected and unfamiliar, severely influences job performance [16]. Furthermore, according to the reports done by this researcher, noise above $90 \mathrm{~dB}$ causes increasing stress, fatigue and increasing rate of errors by physiological stimulus of harmful organism responses and quality and productivity are reducing. An unfamiliar and sever sound also will cause more anxiety and interruption in doing duties and even will cause disorder in verbal communications. Environment which has noise pollution creates reactions which all indicate jeopardizing physical health such as severe headaches, stomach discomfort, unusual fatigue, lowered resistance against damage, extreme vulnerability against the Cardiovascular disease. Work environment noise is also affecting mental health including impatience, irritability, stress, lack of concentration and difficulty. In work environment, noise pollution can threat workers and employees safety seriously. Also, high noise decreases concentration and obviously reduces job quality.

As it is clear in table 1, 32 persons out of 50 persons who are participating in the survey had consensus about high level of work environment noise and only 12 percentage of workers have commented about low level of environment noise. Therefore, the frequency of environment noise by $64 \%$ votes has been received the maximum votes. Diagram 1 shows the results obtained from this environmental factor. It is transparent that being more than 2 hours exposed by even a moderate amount of noise will cause work stoppage, tension, headache and ultimately feedback drop. 


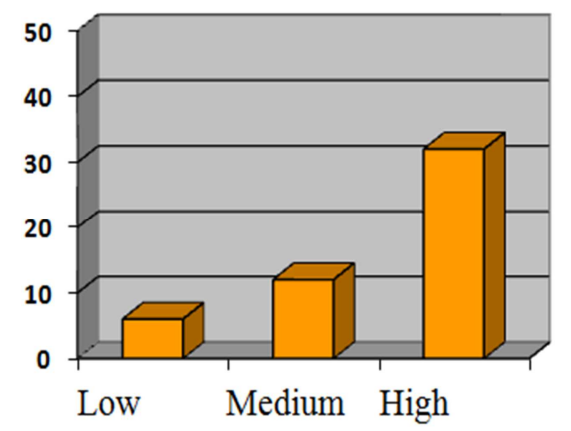

Diagram 1. Results obtained from assessment of environmental factor, noise

Now, if this noise was relevant to the current resources in industrial unit such as source of electricity or other equipment, it can be articulated that this noise can be considerably decreased by proposing strategies. Some of strategies can be referred like replacing these devices with other similar low noise equipment and also more update systems. Another method is to isolate these kinds of resources. To do this, by putting devices in the cabin or a closed container with pores for device ventilation, we can prevent from noise dissemination. Also, to prevent from noise derived from devices' vibration while working, we can fix device in its place using suitable flooring. We can change workers' work shift by performing an especial plan in order to travel between low and high noise places. We can also change workers' work environment by proposing overall plan in the factory and transfer them to the low noise place which is far from devices, but in a sense that none of aforementioned cases is performable, worker has to use ear protection. However, workers should be protected against noise in the best way. Accordingly, negative effects caused by noise on employees performances and also human errors will be decreased. It would be led to increase worker accuracy and thereby high quality productions and also increase in workers' and employers' satisfaction.

\subsubsection{Temperature and Ventilation}

Appropriate temperature condition for the effective work environment is usually $20-24$ centigrade degree with $40-80$ percentage relative humidity. So in this condition, temperature changes should not exceed $4{ }^{\circ} \mathrm{C}$ [9]. Also, ventilation devices are pretty necessary especially for industrial units and they cause airflow exchange. To rebuild breathing air, each personrequires 12 to 15 cubic meters of air per hour.In intensive work condition, this is double increasing[9].

In this industrial unit, among 50 comments, 34 workers (68 percent) have confessed the balance of their work environment temperature and 16 persons believe that work environment temperature is low and none of workers participated in the survey haven't believed that environment temperature is high. Of course, this issue is a little related to the season (autumn) in which survey has been done. Diagram 2 exhibits results of this assessment. To keep air quality in indoor environments; ventilation should be done at least equal to the volume of air per hour.

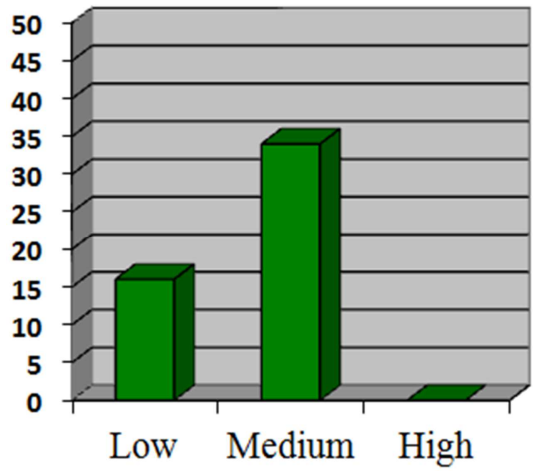

Diagram 2. Results obtained from assessment of environmental factor, temperature

But workplace temperature must be balanced, because very high temperature causes fatigue and drowsiness, physical decrease in performance and increase in danger of afflicting to the mistakes [17] and very low temperature will be job interruption. Work environment with suitable temperature and ventilation causes receiving better oxygen supply by workers and this enjoyable work environment will have positive effect on their performance and also organization's productivity.

\subsubsection{Work Environment and Drinking Water Health}

Environmental health is to control all of factors which have adverse impact on sustainability of human health. Environmental health manages all of individual physical and chemical aspects, apparent biological factors and behavioural effective factors. This matter includes assessing and controlling environmental factors which are potentially effective on health. Environmental health has targeted prevention from diseases and supporting healthy environments. In fact, the main goal of environmental health is to control all of factors which are potentially and practically imposing adverse effects on human survival and health. To reach this goal, it necessitates taking an advantage of environmental knowledge and engineering principles to control; amend and improve environmental physical, chemical and biological factors in order to retain and promote human health and welfare.

In the context of work environment and drinking water health, we have encountered interesting responses. As it is seen in table 1, 50 percent of respondents have referred to average drinking water health and half of them have referred to the lack of drinking water health. Diagram 3 exhibits resultsobtained from assessment of these organizational factors. Also, in the work environment health, 52 percent of workers have commented the lack of health and only 14 percent have considered work environment health and sanitation high.

We can assign programs instead of weekly cleaning; 20 minutes are given to each worker before finishing his work. Applying this policycausesfurthermaintaining health and sanitation in the workplace and enhancement in work space 
will cause to increase workers' satisfaction, incentive and efficiency.

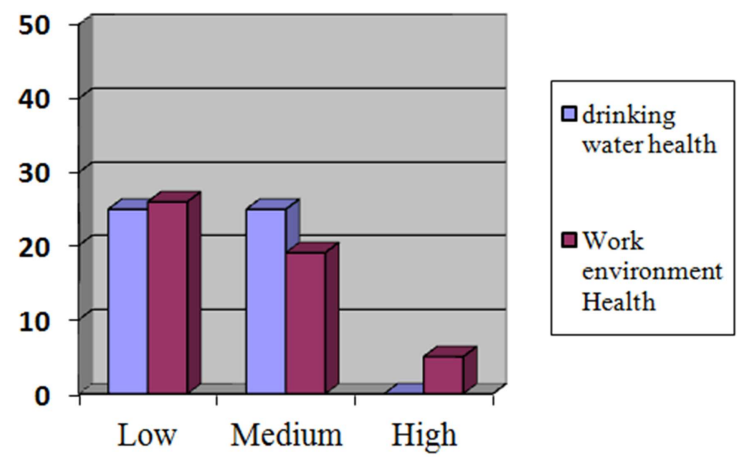

Diagram 3. Results obtained from assessment of organizational factors, work environment and drinking water health

\subsubsection{Work Environment Pollution}

Work environment pollution is one of the factors which have an impressive impact on work process. The less the pollution is, the more tangible the progress in productivity of their activities is. It is inferred from survey that 56 percent of workers have considered work environment pollution high and only 10 percent of them have considered this pollution low. Diagram 4 shows results obtained from survey about this organizational factor.

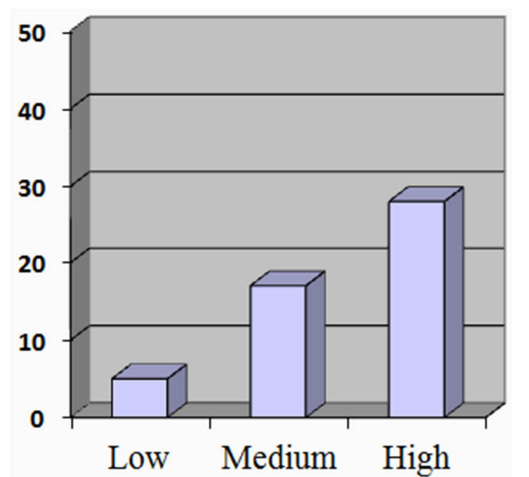

Diagram 4. Results obtained from assessment of organizational factors, work environment pollution

It is natural that in such polluted environment, workers are losing their incentives and their concentration and efficiency will be decreased and this would be along withphysical problems for the workers and organization doesn't gain respective feedback. To resolve this problem, we can use some techniques such as using mask, air purifiers or in a whole, changes in the workers' work environment. We will take this issue into the consideration in the work environment sector. Due to the normalization of the data, pearson parametric test can be used for data analysis. Pearson correlation test results showed in table 2.

As Table2 shows, according to Pearson correlation coefficient and significance level was between productivity and environmental factors, there is a significant positive correlation. The highest level is allocated to work environment and drinking water health.
The results of Table 3 shows that the coefficient of determination adjusted multiple linear combination of environmental factors and the productivity is equal to 0.326 , which means that environmental factors account for 32 percent of the variance in productivity.

Table 2. Pearson correlation test results between environmental factors and total productivity

\begin{tabular}{lcc}
\hline Variables & correlation coefficient & significant level \\
\hline $\begin{array}{l}\text { Noise } \\
\text { Temperature and }\end{array}$ & 0.49 & 0.01 \\
$\begin{array}{l}\text { ventilation } \\
\begin{array}{l}\text { Work environment } \\
\text { and drinking water } \\
\text { health }\end{array}\end{array}$ & 0.54 & 0.01 \\
$\begin{array}{l}\text { Work environment } \\
\text { pollution }\end{array}$ & 0.63 & 0.01 \\
\hline
\end{tabular}

Table 3. results of multiple regression analysis of environmental factors and productivity

\begin{tabular}{lccc}
\hline Variables & $\begin{array}{l}\text { Coefficient of } \\
\text { Determination }\end{array}$ & $\begin{array}{l}\text { Adjusted Coefficient } \\
\text { of Determination }\end{array}$ & significant \\
\hline $\begin{array}{l}\text { Environmen } \\
\text { tal factors }\end{array}$ & 0.329 & 0.326 & 0.01 \\
\hline
\end{tabular}

\subsection{Equipment}

\subsubsection{Machineries Safety}

Fundamentally, to develop projects' safety, prevention policy before action should be used. So that workers are allowed to use equipment only after preventive safety actions. In industrial units, due to this issue that there is a possibility of equipment errors because of high function, burnout and stuff like that, the possibility of dangerous incidences is not unexpected.These events will be led to the closure of all or part of the work.

As it was inferred from obtained data, 64 percent of participants in the survey have emphasised in medium machineries' safety and 16 persons have commented the low equipment safety. Diagram 5 shows results obtained from this assessment.

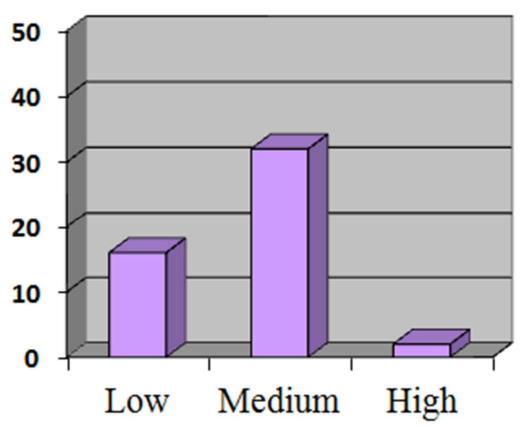

Diagram 5. Results obtained from assessment of equipment factor, Machineries safety

The simplest way to protect work with machineries is to remote human operator from dangerous equipment by putting a physical container between them, but if operator is directly connected to this equipment, it is better to separate all of dangerous parts of machine or at least parts which have 
direct contact with the user or they are protected well by establishment of protective devices in order not to provide contexts for human damages. Also, if unpredicted events are happened, device has to be ready for the sudden stoppage. This issue can be carried out through applying steel cables and leverages in order to reduce financial and lateral damages caused by incidents occurrences, but the best way to obtain incidents is to use Personal Protective Equipment (PPE). These kinds of safety instruments include gloves, hat, boots and glasses. However, periodic control of devices' operations should be considered as the first priority of each industrial unit, because it prevents from errors and delays in project implementation process.

\subsubsection{Using Mask}

Using Personal Protective Equipment (PPE) is generally bothersome. Mask also is one of these kinds of equipment which might harden breathing and cause performance disorder. Furthermore, most of filters will be inefficient against many of gases. As it is observed in survey data, 78 percent of workers haven't used mask and about 11 percent have used it a few. Diagram 6 displays results obtained from survey about this factor.

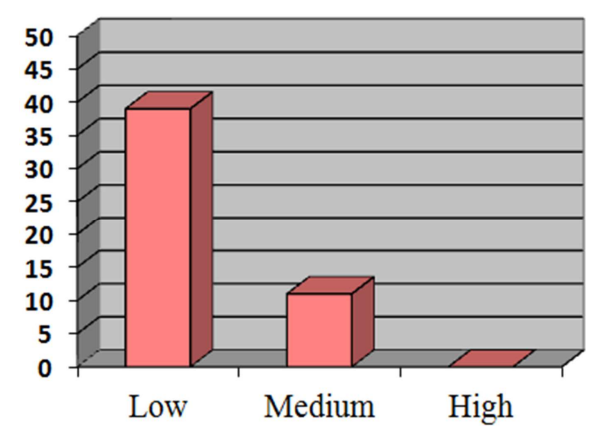

Diagram 6. Results obtained from assessment of equipment factor, using mask

So, Personal Protective Equipment (PPE) always must be employed as the last parapet to defend workers and only in the cases that other resources are inefficient and impractical. Nevertheless, while eliminating or remote worker from dangerous work environment is not possible, matter of using Personal Protective Equipment should be more addressed. Due to the normalization of the data, pearson parametric test can be used for data analysis. Pearson correlation test results showed in table 4.

Table 4. Pearson correlation test results between equipment factors and total productivity

\begin{tabular}{lcc}
\hline Variables & correlation coefficient & significant level \\
\hline Machineries safety & 0.44 & 0.01 \\
Using mask & 0.57 & 0.01 \\
\hline
\end{tabular}

As Table 4 shows, according to Pearson correlation coefficient and significance level was between productivity and equipment factors, there is a significant positive correlation. The highest level of is allocated to the use of a mask.
The results of Table 5 shows that the coefficient of determination adjusted multiple linear combination of factors, equipment productivity is equal to 0.354 , which means that factors in equipment express $35 \%$ of the variance in productivity.

Table 5. results of multiple regression analysis of equipment factors and productivity

\begin{tabular}{lccc}
\hline Variables & $\begin{array}{l}\text { Coefficient of } \\
\text { Determination }\end{array}$ & $\begin{array}{l}\text { Adjusted Coefficient } \\
\text { of Determination }\end{array}$ & significant \\
\hline $\begin{array}{l}\text { Equipment } \\
\text { factors }\end{array}$ & 0.366 & 0.354 & 0.01 \\
\hline
\end{tabular}

\subsection{Physical Factors}

\subsubsection{Surface Inequality}

As data show, 56 percent of workers announced that surface inequality is high which this issue will be followed by waste of worker's useful time, fatigue and performance drop. Diagram 7 displays results obtained from assessment of workers' comments about this physical factor.

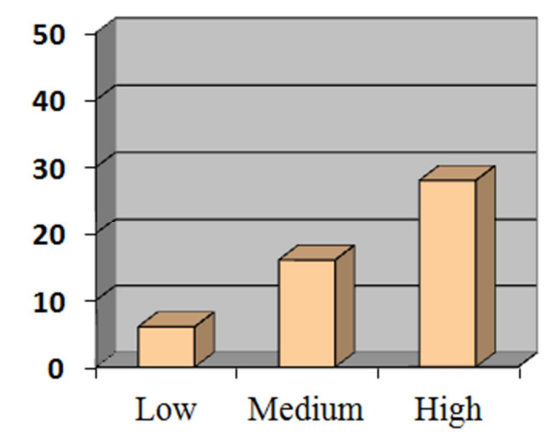

Diagram 7. Results obtained from assessment of physical factor, surface inequality

Enhancements in physical space should be carried out like amending surface inequality so thatparts' transport and especially commuting workers will be safer. This work causes preventing from job accidents and also provides a context for more health in environment.

\subsubsection{Overall Space of Work Environment and Space Allocated to the Worker}

By complicating organizations' structure and performance, organizing work environment either in terms of environmental or in terms of dimensions has to be done so that it would lead to the greater activation of human resources, increasing job incentive, workers' freshness, omitting probable dangers, increasing quality in the work and goods, decreasing depressions, growing productions, growing positive services and eventually achieving respective productivity. Work environment in organizations is one of the critical issues which is continuously proposed. Also, importance and how to create suitable and efficient environment for human resources arealways addressed. A proper environment can be effective on growing personnel values, increasing their ability and productivity. That is why, human management science or ergonomics is so critical for organization mangers and leaders [18]. 
According to the conducted survey, overall space allocated to the assembly unit of this automobile factory is average and low, so that 72 percent of workers ( 36 persons) have mentioned the average work space and 11 persons have emphasized on the lack of space, so that space allocated to the worker has the reverse results. Accordingly, 30 persons out of studied 50 persons, that is, 60 percent of workers have emphasized on the lack of space and 16 persons have emphasized on average space. Diagram 8 shows that assessment of results obtained from this survey.

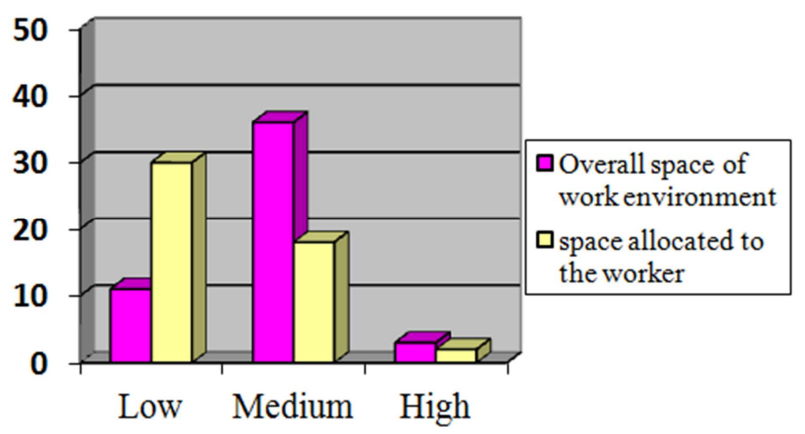

Diagram 8. Results obtained from assessment of physical factor, work space

Psychological researches and investigations indicate that physical condition of work environment has a great effect on mental health of organizations' employees. Appropriate lightening, type of windows, built green space, type of space layout, music, health as well as space color have a considerable effect on personnel performance. Since, employees are spending most of their work time in the work environment, so effect of internal factors on employees' performance is very high. That is why; type of layout and details of internal space of work environment based on type of organization activity and strategy, employees' viewpoint and organizational culture will be variable[19]. Psychological researches show that if physical condition was appropriate in the work environment, it would cause progress productivity and qualitative promotion of employees' work. Due to the normalization of the data, pearson parametric test can be used for data analysis. Pearson correlation test results showed in table 6 .

Table 6. Pearson correlation test results between physical factors and total productivity

\begin{tabular}{lcc}
\hline Variables & correlation coefficient & significant level \\
\hline $\begin{array}{l}\text { Surface inequality } \\
\text { Overall space of } \\
\text { work environment } \\
\begin{array}{l}\text { and space allocated } \\
\text { to the worker }\end{array}\end{array}$ & 0.42 & 0.01 \\
\hline
\end{tabular}

As Table 6 shows, according to Pearson correlation coefficient and significance level was between productivity and physical factors, there is a significant positive correlation. The highest amount is allocated to Overall space of work environment and space allocated to the worker.

The results of Table 7 shows that the coefficient of determination adjusted multiple linear combination of physical factors with productivity equal to 0.452 , which means that physical factors express $45 \%$ of the variance in productivity.

Table 7. results of multiple regression analysis of physical factors and productivity

\begin{tabular}{lccc}
\hline Variables & $\begin{array}{l}\text { Coefficient of } \\
\text { Determination }\end{array}$ & $\begin{array}{l}\text { Adjusted Coefficient } \\
\text { of Determination }\end{array}$ & significant \\
\hline $\begin{array}{l}\text { Physical } \\
\text { factors }\end{array}$ & 0.434 & 0.452 & 0.01 \\
\hline
\end{tabular}

\section{Role of Other Factors}

As it was previously mentioned, in the questionnaire, workers had been asked to mention other cases which cause disorder in their work process. We have obtained interesting statistics. Almost, most of them had complained about production line speed, shortage of people in production line, workers' stress, long work time and thereby short work time, erratic work process, lack of adequate time to do personal affairs which all are accounted as macro-ergonomic factors of work environment. These factors will cause to reduce quality of productions and by customer dissatisfaction; system's productivity is exposed by danger. They can be appropriate indices for the next macro-ergonomic studies.

\section{Conclusion}

Studying work environment in the organizations is one of the critical issues which is continuously proposed in the meetings and papers. Importance and how an efficient and proper work environment in terms of physical and mental aspects for human forces is created, is addressed. It is transparent that a good work environment, either in terms of physical aspect, by providing facilities to decrease human pollutants, continuous attempt to keep work environment safer and decreasing context for work accidents and initiating adornment culture in work environment or in terms of mental aspect, by creating credit and respect and considering justice, all cause emerging honour sense about the work and establishing friendship between employees. Sum of these factors can affect growing personnel values and increasing their ability and productivity. That is why, human management science or ergonomics for consistency between employees with job and work environment has the high importance. Since, factors affecting work are a lot and these factors are directly or indirectly affecting individual health and work, but to have real efficient ergonomics and to meet upcoming decades' needs, it is necessary to involve organizational and managerial factors in the ergonomic studies and programs. Macro-ergonomics is a human-oriented approach for overall fitness of organization designing and the system which is working with human. In fact, macro-ergonomics determines interactions and fitness between each of system's components by analyzing the whole system. The greater assurance of system optimal function and its effectiveness including productivity, safety, welfare, and incentive and work life quality can be known as the 
advantages of applying macro-ergonomic principles in the organizations.

Since, in each industry and production, worker plays an important and determining role in production, quality, and productivity and eventually organization place among competitors, our researches have been carried out in the context of environmental, organizational, physical and equipment factors by collecting data from questionnaires of workers in assembly unit of an Iranian automobile company. This dissertation showed that in the context of environmental factors, low temperature of work environment and high noise of work environment will cause workers' tension and dissatisfaction, while decreasing negative effects derived from noise on employees performance will cause decreasing human errors which are led to increase workers' accuracy and thereby productions with the high quality and also increasing workers' and employers' satisfaction. On the other hand, when activities done by job agent are ongoing, effective temperature also can have the maximum effect on individual job performance. In the context of physical factors, surface inequality in work environment in viewpoint of workers is high which creates some concerns for workers' safety. Also, in relation to the organizational factors, discussions such as drinking water health and work environment health have relatively less assessed. Also, pollution of work environment is high. In safety equipment discussion, job safety was in the moderate level and using mask was too low which asks for an especial attention, because despite high environment pollution, lack of using mask by the workers shows lack of managers' attention to the workers' health and subsequently creating unanticipated problems for the workers and employers.

All of these factors plus factors mentioned by the workers are macro-ergonomic factors. If they are correctly applied in the factory, they will lead to health, safety, workers' incentive and eventually promoting products' quality, customer satisfaction and increasing organization productivity. It has to be articulated that production line speed, shortage of people in production line, workers' stress, long work time and thereby short work time, erratic work process, lack of adequate time to do personal affairs all are the factors which have been proposed by the majority of workers. They can be appropriate indices for the next macro-ergonomic studies.

\section{References}

[1] Abarghoei, N. Sadra, HosseiniNasab, Hassan; Farokhzad, M, "Macro-ergonomics interventions and their impact on productivity and reduce musculoskeletal injuries (including case study)", 2012, Quarterly Journal of Iran's occupational Health.

[2] Helali F. "Developing an Ergonomics Intervention Technique Model to Support the Participatory Ergonomics Process for Improving Work Systems Organizations in an Industrially Developing Country and its 'Meta-Reflection'”, 2008, Doctoral Thesis, Department of Human Work Sciences, Luleå
University of Technology, Sweden.

[3] Helali, F, “The Ergonomics 'Know-how' Transfer Models to IDC's Industries (Concept, Theory, Methodology, Method, Technique)", 2009, U.K and the U.S.A: LAMBERT Academic Publishing AG \& Co. KG.

[4] Kleiner, B.M.; "Macroergonomics as a Large Work-System, Applied Ergonomics"; 2005, Vol 14 (2): 81-89.

[5] Shahnavaz, H; "Making ergonomics a world - wide concept. Ergonomics". 1995, Vol 39 (12) 1391- 1402.

[6] Helali F, Lonnroth, E; Shahnavaz H; "Ergonomics intervention in industries of the industrially developing countries, Case study: Glucosan-Iran”. In: Brown O Jr, HendrickHW, editors. Proceedings of Human Factors in Organizational Design and Management V. Amsterdam, the Netherlands: North- Holland. 2008, p. 141-6.

[7] HendrickHal.W, and Kleiner, B.M; "Macroergonomics Theory, Methods, and Applications"; book, 2002; Lawrence Erlbaum Associates. Publishers Mahwah, New Jersey London.

[8] Abdollahpour, N, "macro-ergonomics and its impact on productivity". 2011, M.S Thesis, Welfare and Rehabilitation Sciences University - Institute of Social Welfare.

[9] Iida, I. "Ergonomia: projeto e produçৎo". 2005, Vol 2. ed. S^o Paulo: EdgardBlücher.

[10] Sandrez, Mark, Mc Cormic, Ernest; "Ergonomics (human factors) in engineering design"; Translate by Mohammad Reza Afzali, Seventh Edition. 1998, Oloom Daneshgahi of Tehran Publication.

[11] Karzar Jedi, R., "The role of ergonomics and its impact on the production, production trends", MS Thesis, Industrial Management Field, Islamic Azad University of Tabriz, 2000.

[12] Forouzanfar, Behzad,"What is ergonomics", Industry and Safety Magazine, 1999, No 46.

[13] Kleiner, B. M.; "Macroergonomic analysis of formalization in a dynamic work system". Applied Ergonomics, Elsevier Science Ltda, 1998, v. 29, n. 4, p. 255-259.

[14] Taheri, Shahnam. N,. "Work and methods evaluation", 1997, Tehran: Arvin Pub.

[15] Abel, S.M., "The extra-auditory effects of noise and annoyance: An overview of research". J. Otolaryngol. 19, Suppl, 1990.

[16] Bragdon, Clifford R. "Noise pollution; the unquiet crisis". Philadelphia, Univ. of Pennsylvania Press [c1971], 1971.

[17] Grandjean, E.; Kroemer, K. H. E. "Manual de ergonomia: adaptando o trabalhoaohomem". 2005, Vol 5. ed. Porto Alegre: Bookman.

[18] Soltani, Iraj; book "productivity of human resources", Isfahan, Arkan Pub, 2005.

[19] Golabchi, M; Yousefi, S., Forouzanfar, M, "prioritizing the role of physical and architectural work in promoting personnel performance in project-based organization",Third International Conference on Construction Industry. 2012, Tehran. 